\title{
Power quality improvement of distribution systems asymmetry caused by power disturbances based on particle swarm optimization-artificial neural network
}

\author{
Ismael Kareem Saeed, Kamal Sheikhyounis \\ Department of Electrical Engineering, College of Engineering, Salahaddin University-Erbil, Erbil, Iraq
}

\begin{abstract}
Article Info
\section{Article history:}

Received Jul 27, 2021

Revised Dec 19, 2021

Accepted Dec 28, 2021

\section{Keywords:}

Artificial neural network Particle swarm optimization Power quality

Total harmonic distortion Unified power flow quality conditioner

ABSTRACT

With an increase of non-linear load in today's electrical power systems, the rate of power quality drops and the voltage source and frequency deteriorate if not properly compensated with an appropriate device. Filters are most common techniques that employed to overcome this problem and improving power quality. In this paper an improved optimization technique of filter applies to the power system is based on a particle swarm optimization with using artificial neural network technique applied to the unified power flow quality conditioner (PSO-ANN UPQC). Design particle swarm optimization and artificial neural network together result in a very high performance of flexible AC transmission lines (FACTs) controller and it implements to the system to compensate all types of power quality disturbances. This technique is very powerful for minimization of total harmonic distortion of source voltages and currents as a limit permitted by IEEE-519. The work creates a power system model in MATLAB/Simulink program to investigate our proposed optimization technique for improving control circuit of filters. The work also has measured all power quality disturbances of the electrical arc furnace of steel factory and suggests this technique of filter to improve the power quality.
\end{abstract}

This is an open access article under the CC BY-SA license.

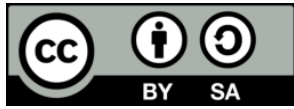

\section{Corresponding Author:}

Ismael Kareem Saeed

Department of Electrical Engineering, College of Engineering, Salahaddin University-Erbil

Kirkuk Road, 44001, Erbil, Iraq

Email: Ismael.Saeed@su.edu.krd

\section{INTRODUCTION}

The reason of the increase in non-linear load is the progression of electronics technology and power electronics systems that cover all areas of our life. Those non-linear loads are the main source of harmonics and missing the source wave sinusoidal. Filter supplementation to the distribution system is the most common way to overcome and eliminate harmonics and return the source wave to its original form. Filters in power systems date back to 1960 s when William Stanley installed a group number of shunt capacitors on industrial power systems to improve power factor. However, after a period of time the use of series reactors equipped with many of those shunt capacitors was introduced, making them into tuned filter banks [1]-[4].

Latterly power electronics tool has speedily prospered globally began with tiny nonlinear loads in our home devices to major manufacturing usages. This has resulted in several power quality problems in the power system, including voltage harmonics and current harmonics, which necessitate being resolved. Initially passive power filters were used to reduce the resulting harmonics at loads, because of simplicity and low cost the passive power filters are used widely in low and medium voltage distribution systems. Although their requirements are much different compare to high voltage power systems. But due to the limitations and 
disadvantages of their use, active power filters were suggested around 1970, and presented to enhance the performance [5], [6]. The possibility of putting active power filters into practical implementations has increased due to advance of power electronics technology. Implementations not just for harmonic reduction, but also include flicker reduction, balancing system and voltage regulation improvement. The shunt active filters have provided much more satisfactory filtration characteristics than classical shunt passive filters or static var compensators. However, active power filters have a very high cost for high rating of power so a hybrid power filters are presented [7]-[10]. Vision-based technology such as using deep learning for useful insights into issues [11], the artificial intelligence and augmented reality developed during the COVID-19 outbreak [12].

According to the researches, a filter or compensator is the best solution to remove the liability of the utilities in light of the existence of specific and wide-ranging impacts on the client or the existence of legislation that requires limited levels of harmonics. Flexible AC transmission (FACTs) are another, and possibly the best way to increase stability, reliability, efficiency and enhance the power quality of the system. Most electrical energy companies aid customers with innovative FACTs to help them receive energy without power disturbance issues [13], [14]. This paper proposes one of the FACTs techniques which is a unified power flow quality conditioner (UPQC) filter that connects to the distribution systems based on particle swarm optimization-artificial neural network (PSO-ANN) in order to get high improvement of power quality.

\section{RIGHT-SHUNT UNIFIED POWER QUALITY CONDITIONER}

Explaining the UPQC is the major filter type to relieve sag voltage issue of nonlinear loads in distribution system, which is a power static elements setup custom power device (CPD). This type of filter can be employed in the power distribution system in two ways right-shunt and left-shunt UPQC at the point of common coupling (PCC) to perform shunt and series compensation. This type of device consists of two voltage source inverters VSIs that feed by common direct current (DC) source. A structure of the voltage source inverter (VSI) built with six H-bridge inverter and six single phase transformers in order to able to inject unbalanced voltages and currents. The power topology diagram and equivalent circuit of UPQC is shown in Figure 1. It shows the right-shunt UPQC compensation configureure uration, the base parts are series transformer, passive filter, voltage source inverter, capacitor, and DC source. This system completely obliterates using the conventional passive filter adjustment procedure, which requires capacitance or inductance correlation for each frequency [15], [16]. The series part of the filter is connected with the power system through injection transformer and filter set, which injects a voltage in series with the power system voltage. The series part of UPQC is the same as dynamic voltage restorer (DVR) filter performed injecting or absorbing reactive power or real power to compensation for voltage sags.

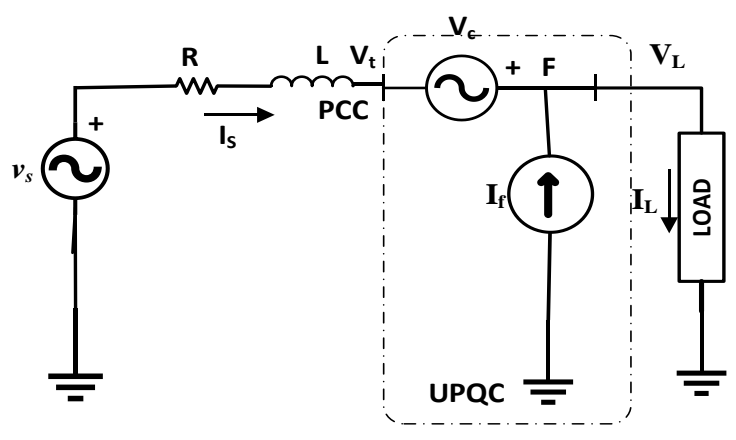

Figure 1. Power topology diagram of UPQC

At the essential part of the UPQC filter is the inverter which is a static power electronics device three-phase voltage source that inverts DC to AC also converts AC to DC. So, we need DC power and a fast switching DC source to perform power compensation. The continuous comparison of source voltage waveform with reference voltage is the main function of the series part filter. When any disturbance occurs in the system, three single-phase AC output voltages from series part filter injects into the system with compensation of amplitude, phase and all integer and interharmonic content. This led to secure the process of unnecessary voltage disruption to the load and sending the desired voltage waveform to the consumers. DC voltage feeds into the input of inverter by DC source in the UPQC filter, the output inverter voltage controlled by three single phase bridge, these resulting bridge voltages are independently filtered and controlled to permit each phase to be separately compensated before feeding to the secondary side of series 
transformer. The primary side of the series transformer must carry the maximum inverter output voltage transform from secondary side of series transformer and also must carry the full line amount current [17]-[19].

Most voltage dips are asymmetric, or unbalanced, in such case the series filter part in UPQC can draw energy from the distribution system side and transfer it to the filter side. In the event of a more severe dip the series filter must exchange active power with the line and draws energy from DC storage system; normally a capacitor. Energy is exchanged between the DC link and storage capacitors by a DC-to-DC voltage conversion circuit. During the sag voltage events, the series filter is recharged by the energy storage source from the distribution system. The active series part filter is inwardly produced reactive power without any passive reactive elements which alternated between the UPQC and the AC system [20]. Control voltage of the series part of UPQC is (1),

$$
V_{C}=V_{L}-V_{t}
$$

if the terminal voltage $V_{t}$ is unbalanced, $V_{C}$ must eliminates this unbalance, so from this condition we get,

$$
V_{C_{-} 0}=-V_{t_{-} 0} \text { and } V_{C_{-} 2}=-V_{t_{-} 2}
$$

suppose $V_{L_{-} 1}=\left|V_{L_{-} 1}\right| \angle 0^{0}$, the inject positive sequence voltage to the system is (3),

$$
\left|V_{C_{-} 1}\right|^{2}-2\left|V_{L_{-} 1}\right|\left|V_{C_{-} 1}\right|+\left|V_{L_{-} 1}\right|^{2}-\left|V_{t_{-} 1}\right|^{2}=0
$$

for shunt current injection part of UPQC we have (4),

$$
I_{s h}=I_{S}-I_{L}
$$

in a same way $I_{F}$ must eliminates the unbalance of $I_{L}$, so the zero and negative sequences of the load current are removed by injecting the current shunt filter portion as shown in the (5).

$$
I_{S h \_0}=I_{L_{-} 0}, I_{S h_{-} 1}=0 \text { and } I_{S h_{-} 2}=I_{L_{-} 2}
$$

From (1) to (5) the right-shunt UPQC eliminates unbalances in the source voltages and unbalances in the load currents. In complete series and shunt compensation only positive sequence of source current will flow through the system. Since only positive sequence current passed through series compensator, and the negative and zero consumed power in it will be zero. Therefore, the active power injected by series filter will be zero. The active control power be (6).

$$
P_{\text {cont }}=P_{\text {Load }}-P_{\text {System }}
$$

The increase of voltage drop lead to increase the active power, so control power is rising, but at phase-angle bound the relationship is losing the linearity. However, it relies on the power factor. In case of interruption a series voltage controller is not present. It needs a closed path for the load current, which is not always present during an interruption. The shunt filter only injects reactive power because there is no positive sequence of current injection, i.e. injecting active power is zero. The formulas for active power and reactive power in the shunt filter can be written as (7) and (8).

$$
\begin{aligned}
& \left|V_{L_{-} 1}\right|\left|I_{F_{-} 1}\right| \cos (\theta)=0 \\
& \left|V_{L_{-} 1}\right|\left|I_{F_{-} 1}\right| \sin (\theta)=\beta * q_{L}
\end{aligned}
$$

UPQC filter overcome and improve the physical constraint of the harmony passive filter, through composition of hybrid system and a control technique circuit. As mentioned before UPQC consist of two part filters shunt and series, each part of filter is consisted of the power circuit and the control circuit. The power circuit composes of a VSI-based pulse width modulation (PWM) and DC source or capacitor to maintain and adjust DC voltage. It is responsible for tuning the desired compensation current. The control circuit controls the power circuit by tracking the harmonic current variation and this is done by determining the instantaneous reference compensation current and precisely tuning the required harmonic current for the control circuit. In the following subsection we will discuss the process of minimization total harmonic distortion in the power distribution system which depends heavily on harmonic extraction and current control techniques [21]. The 
terminal voltage, load current and the reference shunt filter current that eliminate the harmonic part in load current is expressed,

$$
\left.\begin{array}{l}
V_{t}=V_{t}^{\text {Fund }}+V_{t}^{\text {harm }} \\
I_{L}=I_{L}^{\text {Fund }}+I_{L}^{\text {harm }} \\
I_{F_{-} \text {ref }}=I_{F}^{\text {Fund }}+I_{L}^{\text {harm }}
\end{array}\right\}
$$

where $I_{F}{ }^{F u n d}$ is determined by using (5) and (8). In same way the reference of series filter voltage is,

$$
V_{C_{-} r e f}=V_{C}^{\text {Fund }}-V_{t}^{\text {harm }}
$$

\section{PROPOSED PSO-ANN BASED DESIGN}

The major role of UPQC is to inject the appropriate compensating current at PCC with the aim of making the source current and voltage to sinusoidal with a minimum total harmonic distortion (THD). The parameters of the control design circuit are responsible of the value and wave shap of the compensation current and the THD of the resulting both voltage and current source [22]. Any omission of the design circuit leads to failure in compensation. In this paper, the development of parameters prediction of proportional integral (PI) controller circuit in UPQC control circuit using PSO, for minimizing time to get optimal parameters using ANN technique. The innovative phase of this paper is the expansion of PSO-ANN incorporated optimization system for optimizing procedure parameters for smart control of PI controller procedure applicable to industrialization. The system achieves optimum parameters for economical component production resulting in improved the power quality. The paper designs the UPQC model that includes the perfect value of components $L_{s h}, L_{f}, C_{f}, T_{r}, V_{d_{-} r e f}, K_{p}$, and $K_{i}$. This work is done by applying PSO with ANN to the model, these values can be represented as a problem variables and it need to formulate an objective function [23].

PSO is a technique based on random optimization it progressed through recent research, complex problem includes multi-variable, nonlinear and many constraints, therefore, this method is very suitable for optimizing those problems. The process of optimization is started with number of random solutions then the system updates with new velocity and position for each of iteration until optimum values are reached. The updated particle can be found according to the following formula,

$$
\begin{aligned}
& v_{m, n}{ }^{k+1}=\omega * v_{m, n}{ }^{k}+c_{1} * r_{1} *\left(P_{\text {best }_{m, n}}-x_{m, n}{ }^{k}\right)+c_{2} * r_{2} *\left(G_{\text {best }_{m, n}}-x_{m, n}{ }^{k}\right) \\
& x_{m, n}{ }^{k+1}=x_{m, n}{ }^{k}+v_{m, n}{ }^{k+1}
\end{aligned}
$$

where $v_{m, n}=$ particle velocity $\mathrm{m}$ when iterating $\mathrm{n} ; x_{m, n}=$ particle current position $\mathrm{m}$ when iterating $\mathrm{n} ; P_{\text {best }}=$ particle personal best $\mathrm{m}$ in the group when iterating $\mathrm{n} ; G_{\text {best }}=$ particle best position $\mathrm{m}$ in the group when iterating $\mathrm{n} ; r_{1}$ and $r_{2}=$ random number 0 and 1 ; and $c_{1}$ and $c_{2}=$ learning factors are taken as 1.5. PSO has an information sharing mechanism that is preferred over other optimization techniques. The objective function of pi controller of the UPQC device can be written as (13). The best possible solution only is to find evolution, so all particles quickly tend to converge towards the optimum state [24]-[28]. Table 1 shows the parameters chosen for the simulation to obtain optimum value of $K_{p}$ and $K_{i}$ of PI controller.

$$
\omega_{t}=\mathrm{K}_{p} V_{o q}+K_{i} \int_{0}^{t} V_{o q} d t
$$

Table 1. Parameters of PSO algorithm

\begin{tabular}{lc}
\hline \multicolumn{1}{c}{ Parameters } & Values \\
\hline Population size & 50 \\
No of iterations & 100 \\
Wmin & 0.9 \\
Wmax & 0.1 \\
C1=C2 & 1.5 \\
Min offset & 200 \\
\hline
\end{tabular}

ANN is detected as one of the intelligent implement for finding the relationship between inputs and outputs for a complex manufacturing process. It is an information processing structure that including a huge 
number of uncomplicated and highly complicated processing components similar to a biological neural system. The Levenberg-Marquardt algorithm is used to train the neural network. Learning rate, number of training, number of hidden layers, number of neurons in the hidden layers and processing function used are some of the factors that the ANN model relies on most for predictive accuracy and efficacy. An input layer with three neurons, a hidden layer and an output layer with one neuron used in the network. The neuron output can be found by summation of input neuron weight in prior layer with its own bias [29]. Each neuron output in the hidden or output layer is determined by the (14).

$$
n_{i}=\mathrm{f}\left(\sum_{\omega_{i, j}} n_{j}+\theta_{1}\right)
$$

The Simulink was designed using the neural network tool box available in matrix laboratory (MATLAB) version R2018a. The Simulink build with nonlinear input-output in dynamic time series application. Inputs are an 8,001x3 matrix, representing dynamic data: 8,001 time-steps of 3 elements, targets are an 8,001x1 matrix, representing dynamic data: 8001 time-steps of 1 element. For validating and testing data $70 \%$ of target time-steps selected for training, $15 \%$ selected for validation and $15 \%$ for testing. The number of hidden layer neurons was changed from 1 to 10 and the network epoch 6 times in each case. In the end the optimum output of network is acquired with network architecture is 3-10-1-1. The progress of ANN based prognosticate model for prognosticating the components of the PI controller in a UPQC filter shown in Figure 2.

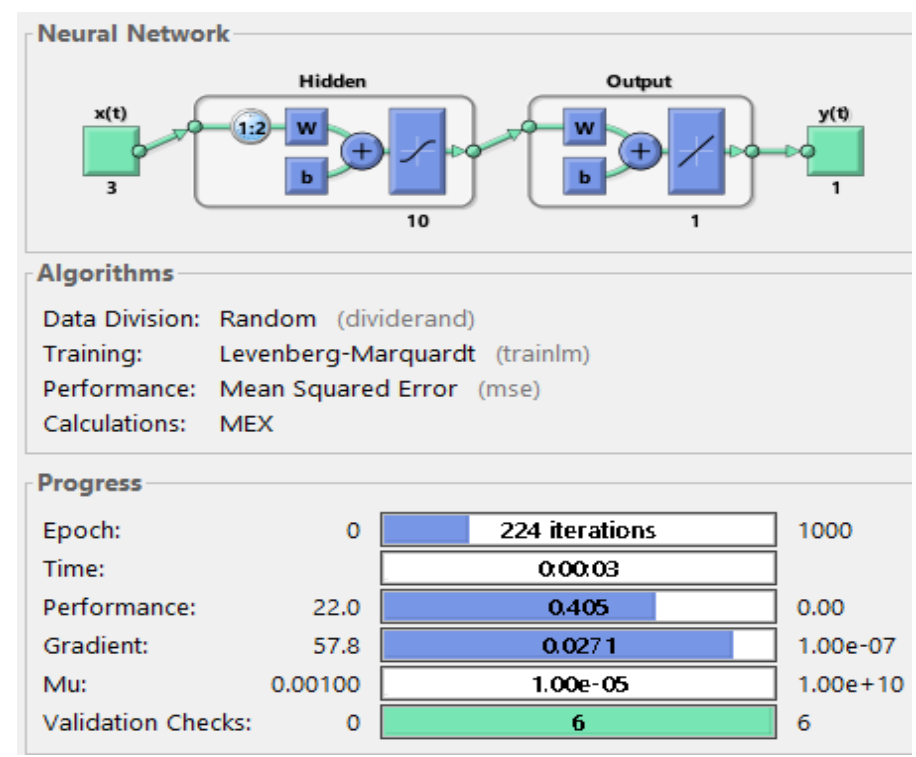

Figure 2. Proposal neural network training

In this paper, the control circuits of getting a desired signal gate of UPQC inverters build upon a versatile control technology which based on the synchronous reference frame (SRF) theory, to mitigate voltage sag problem and to eliminate harmonics for sensitive loads in distribution system. One of the applications of the Park's transformation is applied to control of UPQC which convert the voltage or current from abc signal to dqo reference frame quantities. The quantities can be signifying as the instantaneous space vectors. The performance of UPQC filter depend mainly on its control technique circuit, PSO-ANN takes place of PI controller and phase locked loop (PLL) to control voltages and currents and generate the satisfy pulse signal to insulated-gate bipolar transistor (IGBT) in the control circuit. Figure 3 shows the steps of the entire work flow chart algorithm. The control technique has ability to straight balance in addition with imbalanced sag. An efficient way to organize DC link capacitor voltage of shunt and series filter is deduced. Performance of series and shunt filters with this control circuit is implemented using MATLAB/Simulink technique. Simulation results show the validation of the control technique circuits for UPQC to normalize voltage dip to reduce total harmonic distortion. 


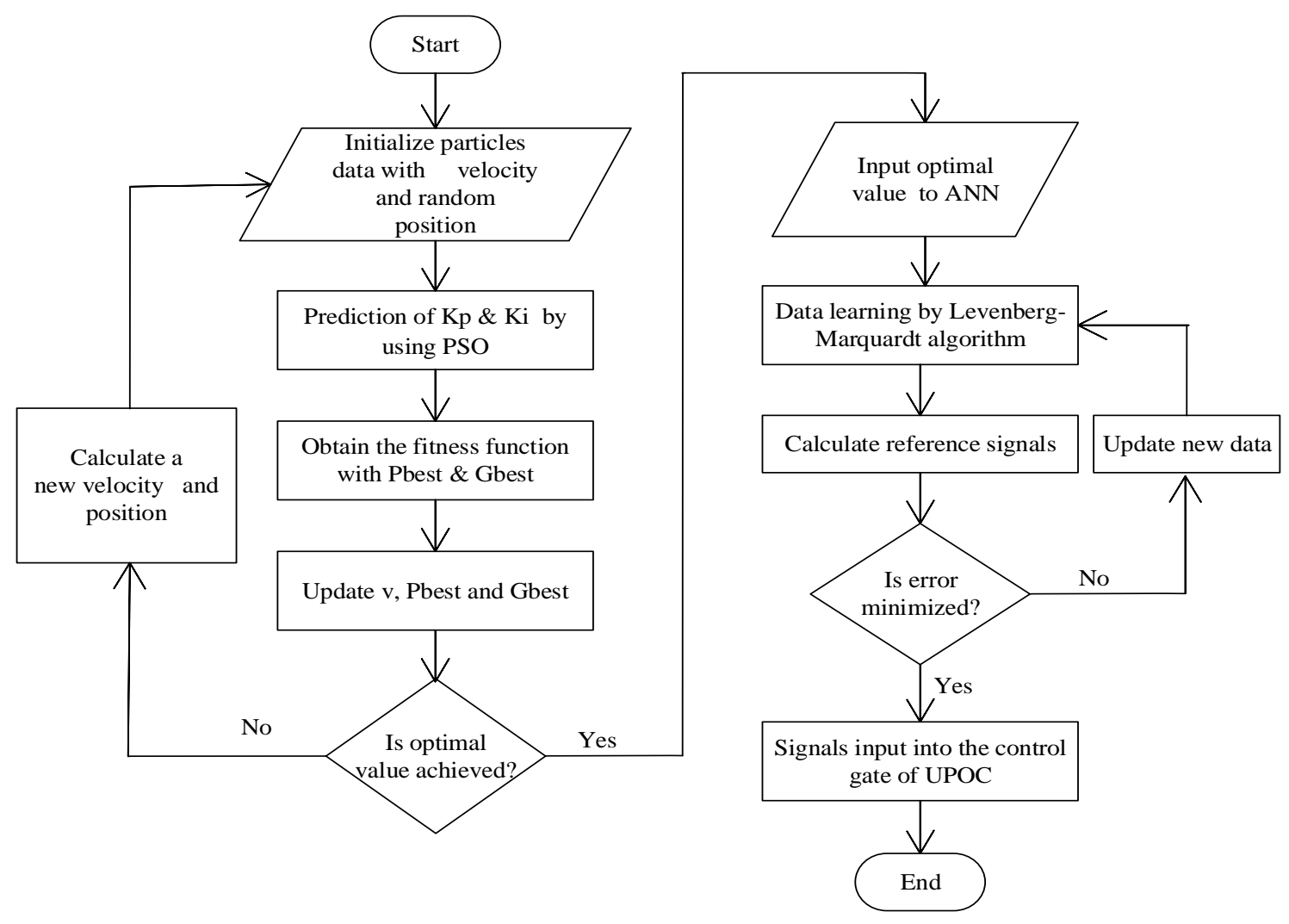

Figure 3. Flow chart of PSO based ANN optimization methodology

\section{CASE STUDY}

To analysis and study the power quality by the proposal filter system, a bundle of data was taken from the electrical arc furnace of Erbil Mountain Steel Industrial Factory as a case of study. All data were measured and taken by the A-EBERLE model PQ-Box 200 device which is power quality analyser/high frequency recorder. Frequency deviation, transient overvoltage $(10 \mathrm{~ms})$, voltage changes, THD, long time flicker, voltage unbalance, voltage harmonic and ripple control are recorded and analysed. Figure 4(a) shows all the data of arc furnace recorded and measured according to EN50160/IEC61000-2-2 standard for one week and all power quality disturbances of the system are compensated by a classic passive filter. It about 569 events occurred to the three lines of the system. Green line is the limit value according to the threshold of the selected standard EN5060 and IEC61000-2-2, red colour column shows the reading of 95\% value, 100\% value shows by blue colour column and the blue column is cross hatched red represent $100 \%$ value limit exceeded. The three-line harmonics for the sample period of the case is shown in Figure 4(b). It shows that harmonic orders $27,33,39$, and 45 in line three are $100 \%$ exceeds the limit.

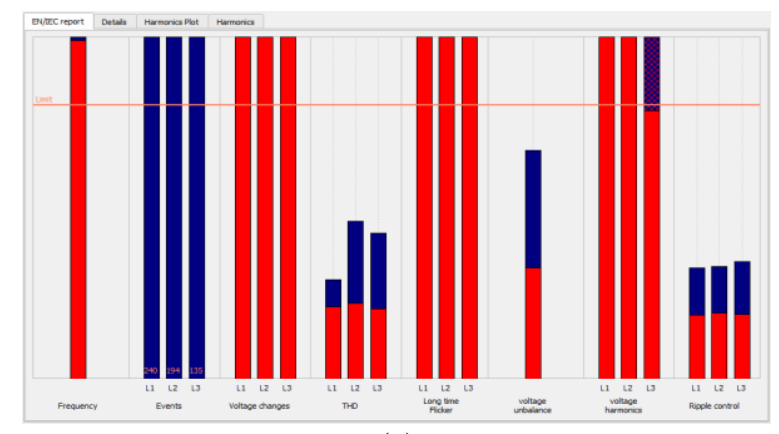

(a)

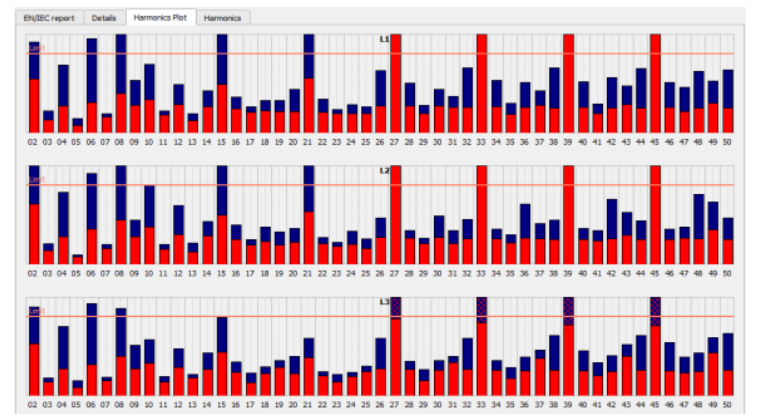

(b)

Figure 4. Erbil Mountain steel factory: (a) standard report plot and (b) three-line voltage harmonics 
The maximum value of frequency is $50.89 \mathrm{~Hz}$ and minimum value is $49.11 \mathrm{~Hz}$ recorded where the maximum and minimum limit value is $50.50 \mathrm{~Hz}$ and $49.50 \mathrm{~Hz}$ respectively. A huge number of flickers occurred by all lines, first line 7.86, second line 7.95 and third line 7.89 , much more than the limit value. The information technology industry council (ITIC) curve representation for all the voltage events shown in Figure 5, all deviations from the nominal voltage in duration and amplitude are displayed graphically, and all data didn't exceed permissible limit.

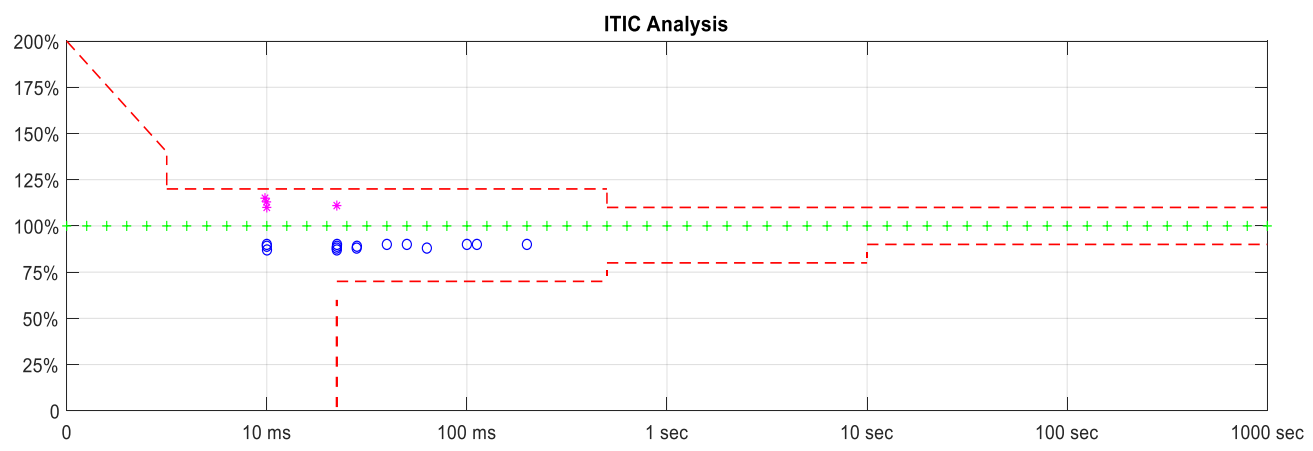

Figure 5. ITIC curve of Erbil Mountain steel factory

\section{SIMULATION AND RESULT}

The study used Matlab R2018a Simulink simcap power system, the simulation of the proposed work is shown in Figure 6. The Simulink parameters shown in Table 2 were chosen to be the best values to obtain the optimum results. UPQC connect to the distribution line system and has taken balanced and unbalanced linear and nonlinear loads, also has taken three types of faults and two types of outage lines.

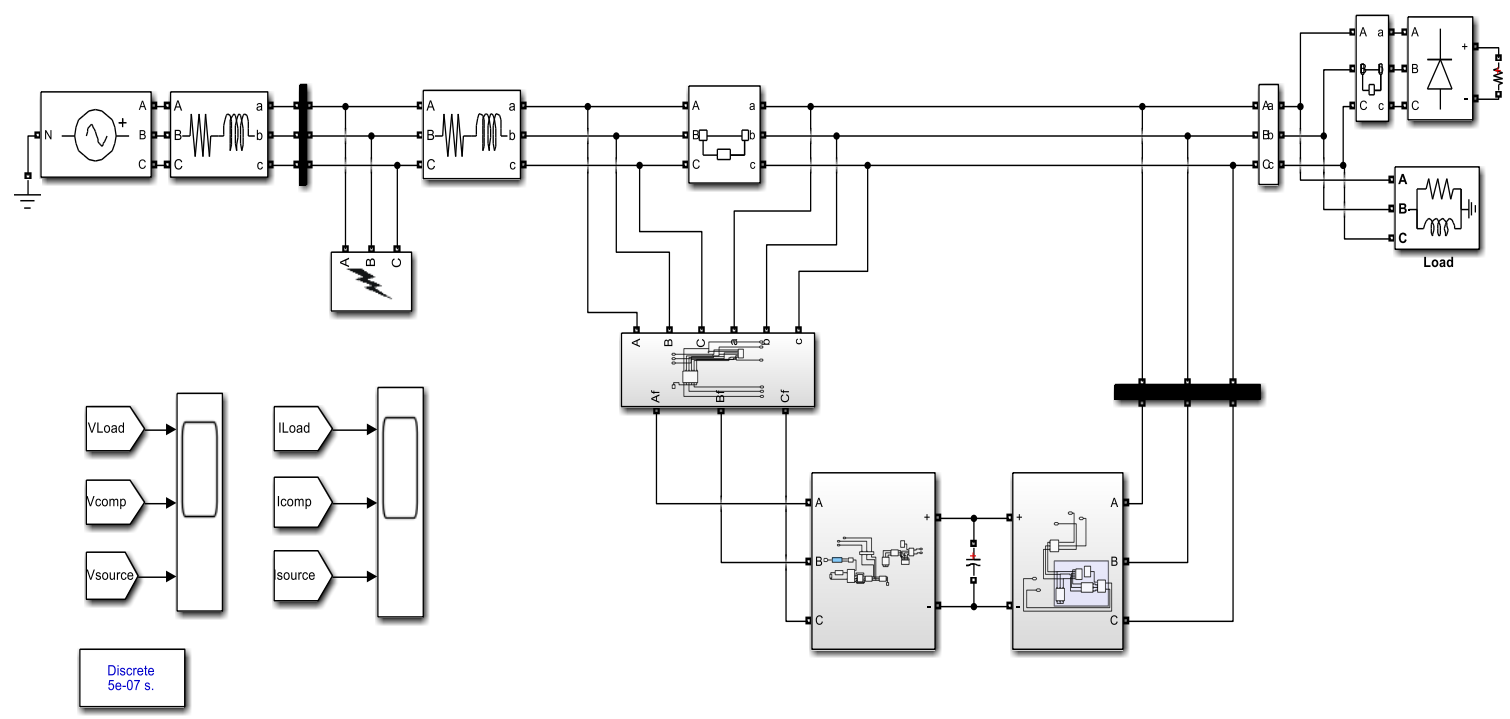

Figure 6. Schematic diagram of PSOANN based UPQC filter

Table 2. Simulink parameters

\begin{tabular}{lc}
\hline \multicolumn{1}{c}{ Parameter } & Value \\
\hline AC source voltage & $400 \mathrm{~V}_{\mathrm{L}-\mathrm{L}}$ \\
Frequency & $50 \mathrm{~Hz}$ \\
Source impedance & $\mathrm{Rs}=0.01 \Omega, \mathrm{Ls}=5 \mathrm{mH}$ \\
RL Filter impedance & $\mathrm{Rs}=0.0 \Omega, \mathrm{Ls}=5 \mathrm{mH}$ \\
RC Filter impedance & $\mathrm{Rs}=5 \Omega, \mathrm{Ls}=20 \mu \mathrm{F}$ \\
DC-link capacitor & $3000 \mu \mathrm{F}$ \\
\hline
\end{tabular}


The control block diagram induce the deserve signal gate of inverter series part of UPQC device shown in Figure 7(a) and the shunt part of UPQC device shown in Figure 7(b), with the benefit of using the park transformation. The optimal values of 0.978 for $K_{i}$ and 16.836 for $K_{p}$ were obtained from the simulataion of PI controller by using PSO method, then the Simulink is run with ANN to get the best results to improve the power quality. The equivalent impedance of the shunt filter circuit is very small and this prevents the harmonic load current path from reaching the grid forming converter, therefore, the harmonic current instead of passing through the voltage source, it will go into the filter branch and it begins the process of compensation. For given a certain frequency an inductive reactance must be formed to electronically adjust the shunt filter of UPQC, since a capacitor bank composed the passive part of a shunt filter. The structure is able to perform various tuning frequencies at the same time, by generating different active reactances for specific desired harmonic.

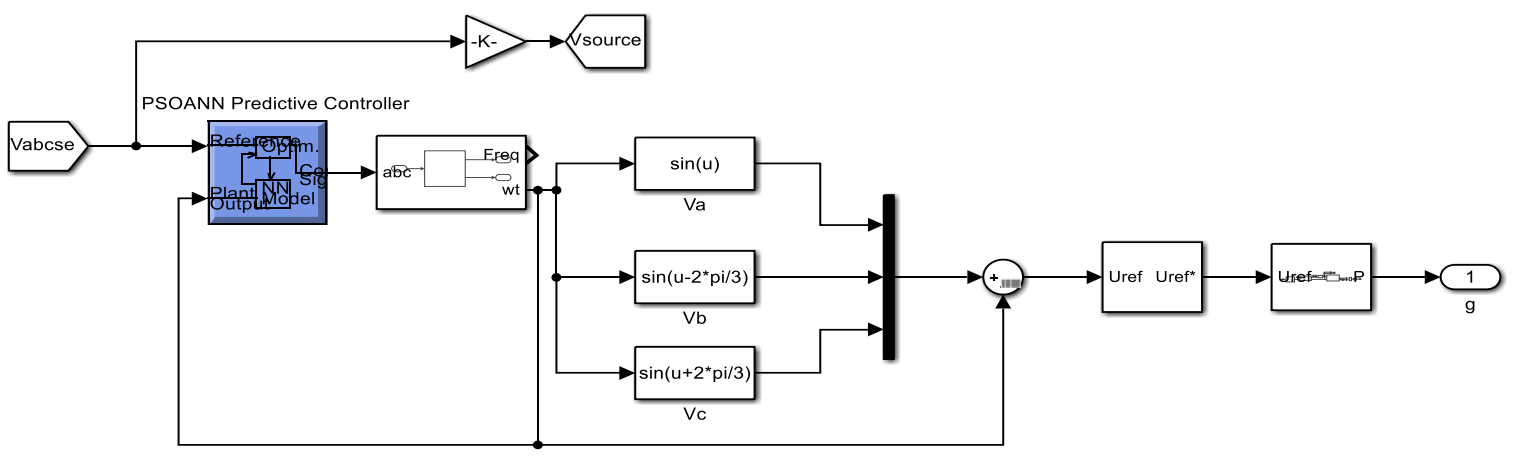

(a)
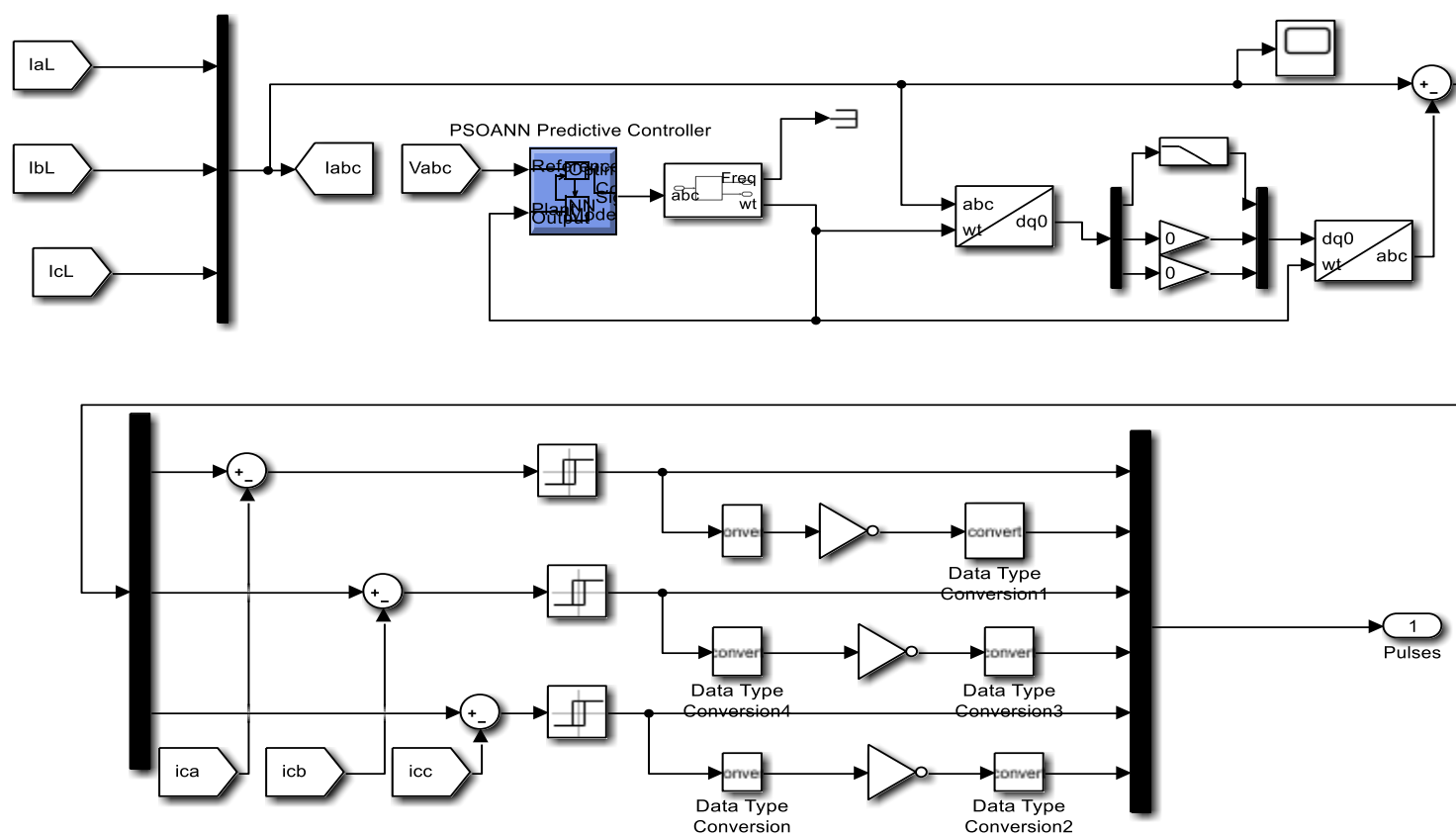

(b)

Figure 7. Proposed PSOANN of UPQC system simulation controller: (a) series side filter and (b) shunt side filter

First, the Simulink run with balanced source applied to the balanced load, in which case the compensation is zero and doesn't have any effect on the load currents. Three signals of load currents, compensation currents and source currents are shown in Figure 8(a). Then the Simulink run with an unbalanced load, and it compensated with proposed PSO-ANN to remain source currents in balanced as shown in Figure 8(b). 
Next, the Simulink run with balanced nonlinear load, Figure 9(a) shows voltages compensation and Figure 9(b) shows currents compensation in a balanced nonlinear load. The fast fourier transform (FFT) analysis have been done for the current source signal and all harmonic orders have been calculated and most of odd harmonics are exceed the limit value according to EN5060 and IEC61000-2-2 standard as shown in the Figure 10(a). THD had become very low and harmonic orders of source current reduced in limit with standard values as shown in Figure 10(b), it seen that THD reduced from 28.54-0.81\%.
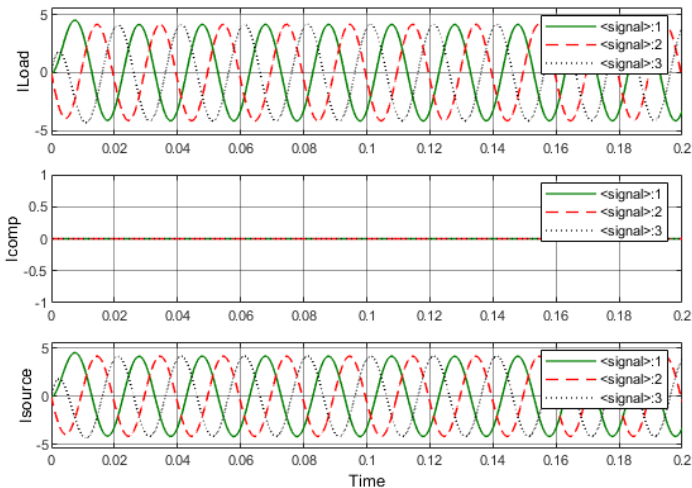

(a)
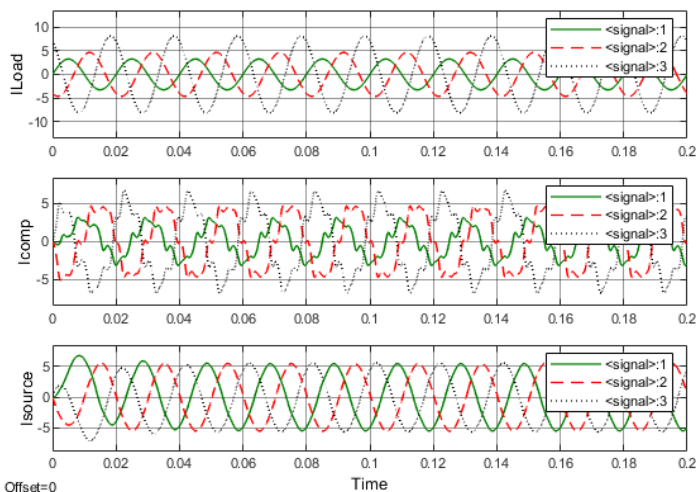

(b)

Figure 8. System current response for (a) balanced linear load and (b) unbalanced linear load
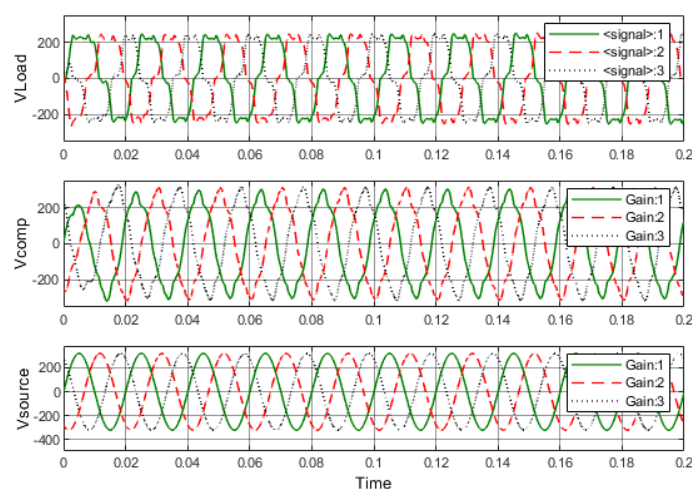

(a)
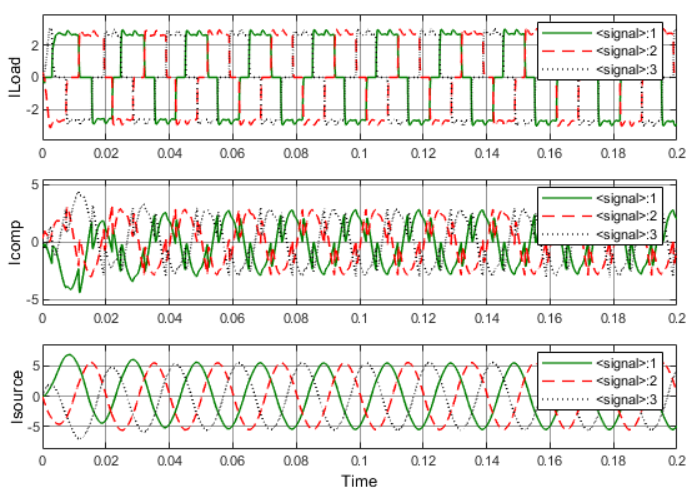

(b)

Figure 9. System response for balanced nonlinear load: (a) voltages response and (b) currents response

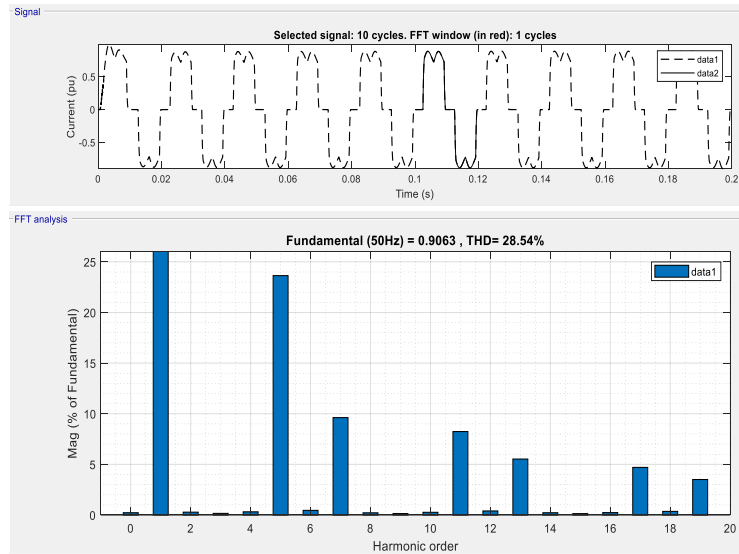

(a)
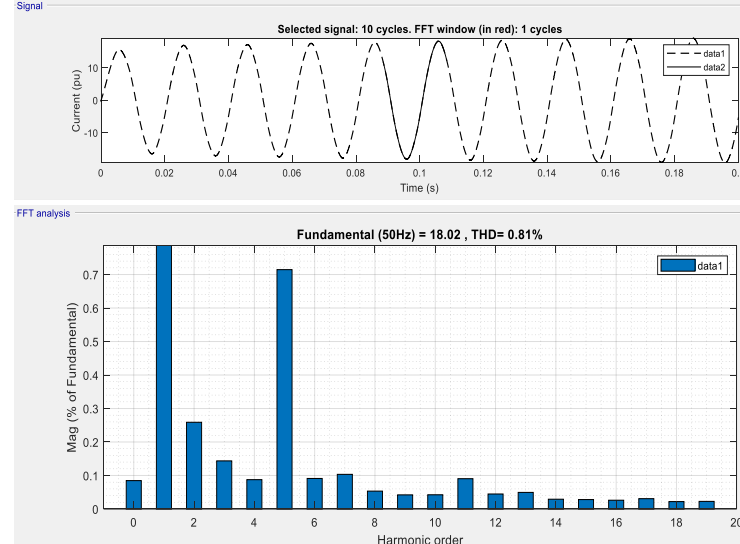

(b)

Figure 10. FFT analysis of balanced nonlinear load current: (a) before optimization and (b) ffter optimization 
Then, the Simulink run with unbalanced nonlinear load, Figure 11 shows currents compensation in unbalanced nonlinear load. The FFT analysis have been done for the current source signal and all harmonic orders have been calculated and most of odd harmonics exceed the limit value according to EN5060 and IEC61000-2-2 standard as shown in the Figure 12(a). THD had become very low and harmonic orders of source current reduced in limit with standard values as shown in Figure 12(b), it seen that THD reduced from $16.03-1.03 \%$. So, this type of optimization can be chosen as the best option for our study case.

After that, the Simulink run with occurrences of $60 \%$ drop voltages from 0.04 to 0.08 second and $140 \%$ over voltage from 0.12 to 0.16 second in the source side voltage. It seen from the Figure 13 , that the load voltage full compensated by proposal compensator. Finally, the Simulink run with occurrence of three types of faults and outage lines, Figures 14(a) and (b) shows voltages response and currents response respectively at one-phase to earth fault occur to the system. Figures 15(a) and (b) shows voltages response and currents response respectively at two-phase to earth fault occur to the system, Figures 16(a) and (b) shows voltages response and currents response respectively at three-phase to earth fault occur to the system. Figures 17(a) and (b) shows voltages response and currents response respectively at open one-phase of nonlinear balanced load power system, and lastly Figures 18(a) and (b) shows voltages response and currents response respectively at open two-phase of nonlinear balanced load power system. It seen that, at occurrence of fault near source the load voltages and currents are full compensated, and at time of lines open near the load the source voltages and currents been full compensated by proposal compensator.
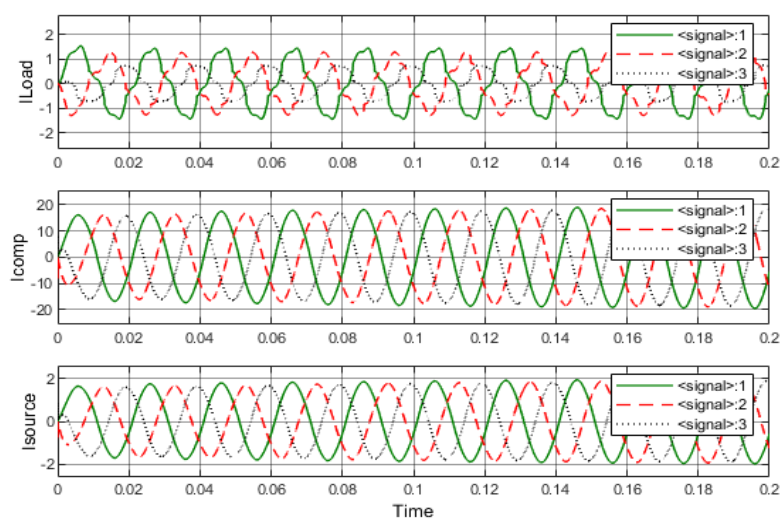

Figure 11. System currents response for unbalanced nonlinear load

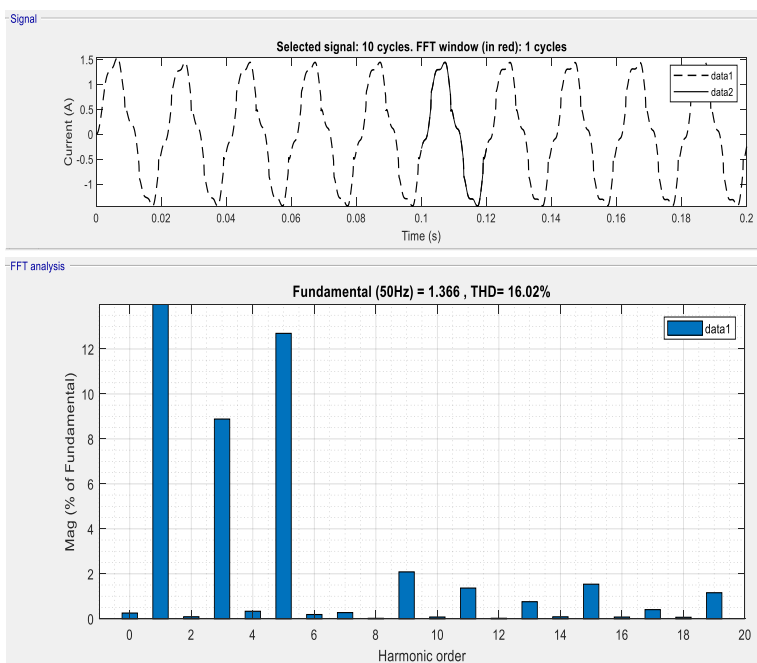

(a)

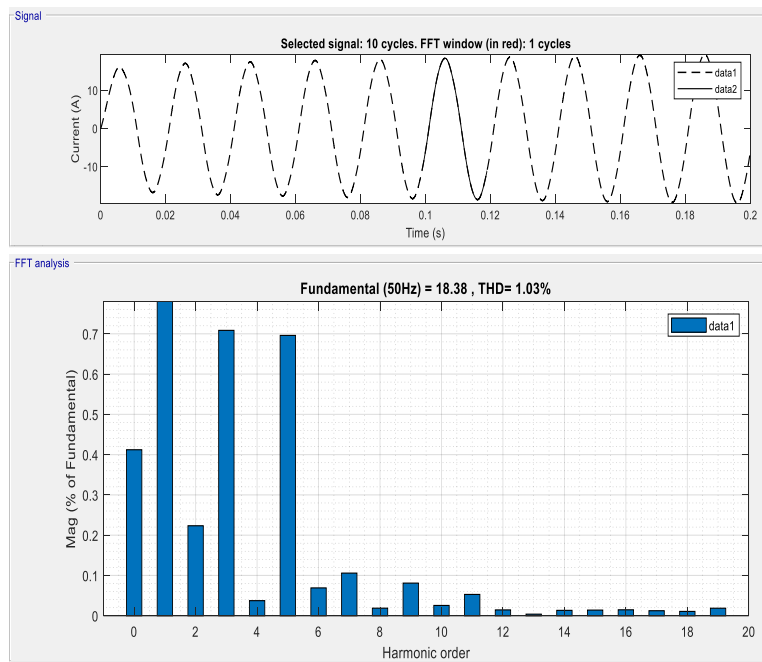

(b)

Figure 12. FFT analysis of unbalanced nonlinear load current: (a) before optimization and (b) after optimization 


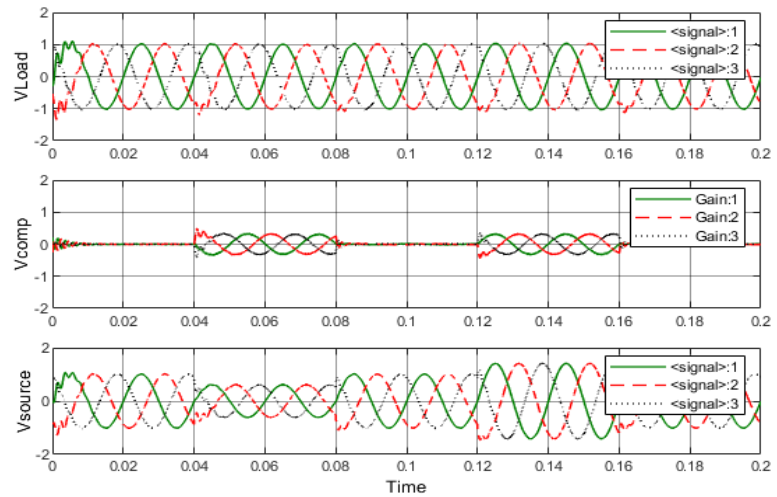

Figure 13. System voltages response for different sag and swell of voltage source

For work evaluation, Table 3 presents the outcomes before and after compensation of THD, for different works. The tabular comparison shows balanced and unbalanced test and it is possible for other tests. It is seen that the proposed method is superior to the other methods in reducing the total harmonic current compensation THD.
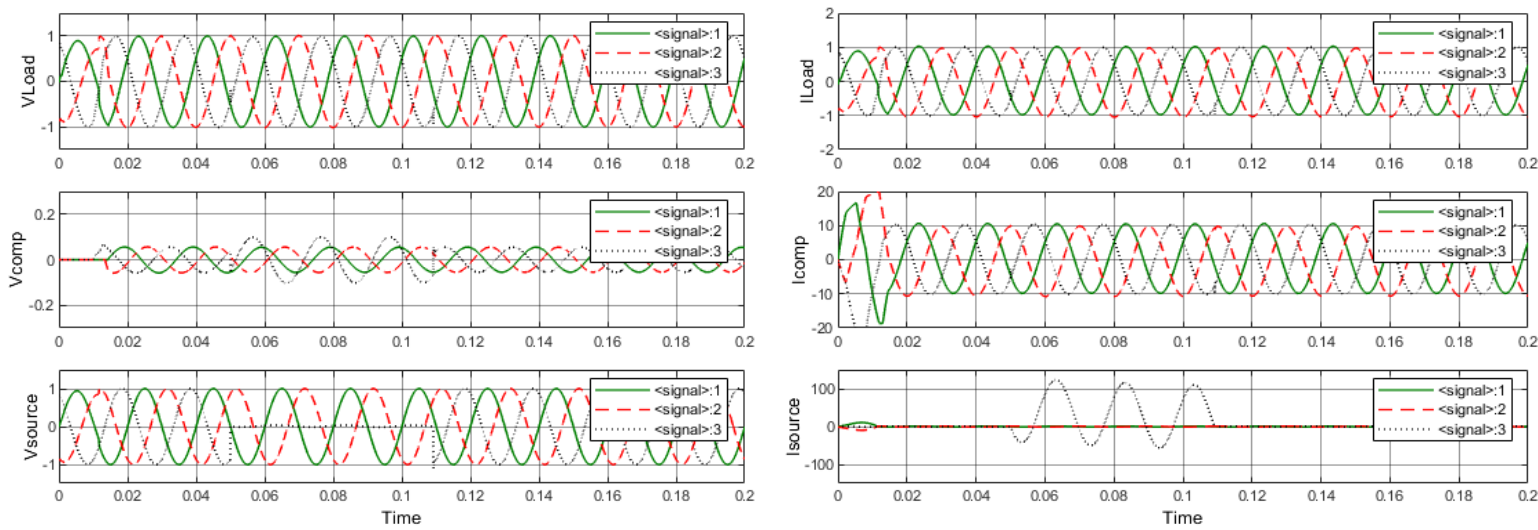

(a)

(b)

Figure 14. System response for single-line to earth fault: (a) voltages response and (b) currents response
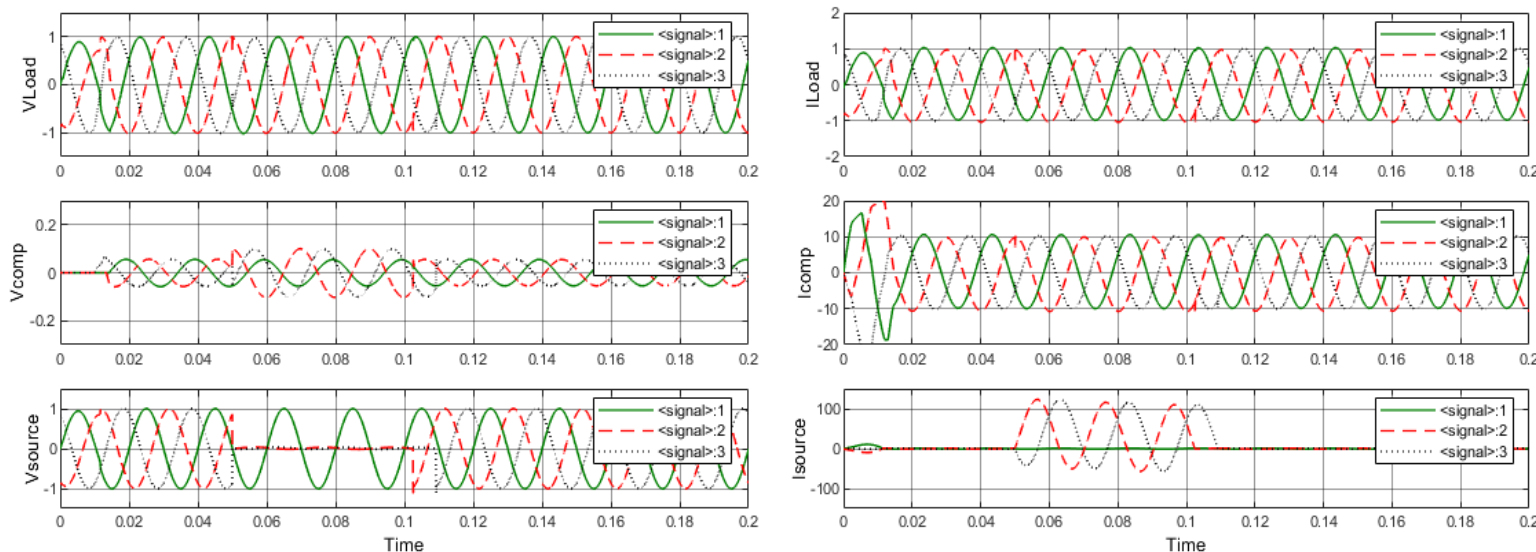

(a)

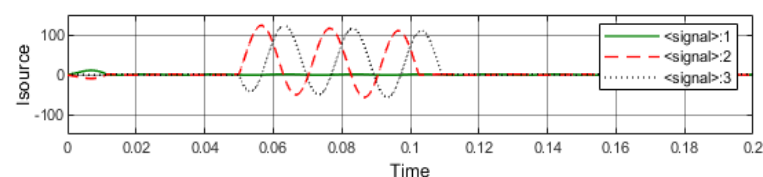

(b)

Figure 15. System response for double-line to earth fault: (a) voltages response and (b) currents response 

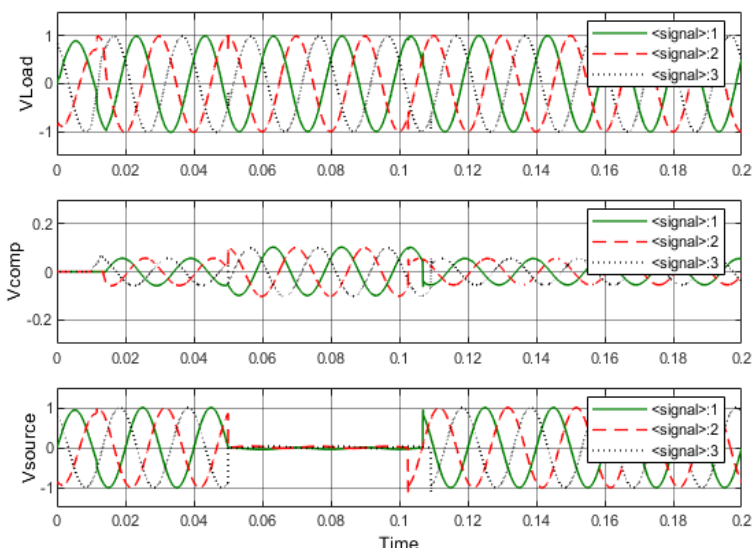

(a)
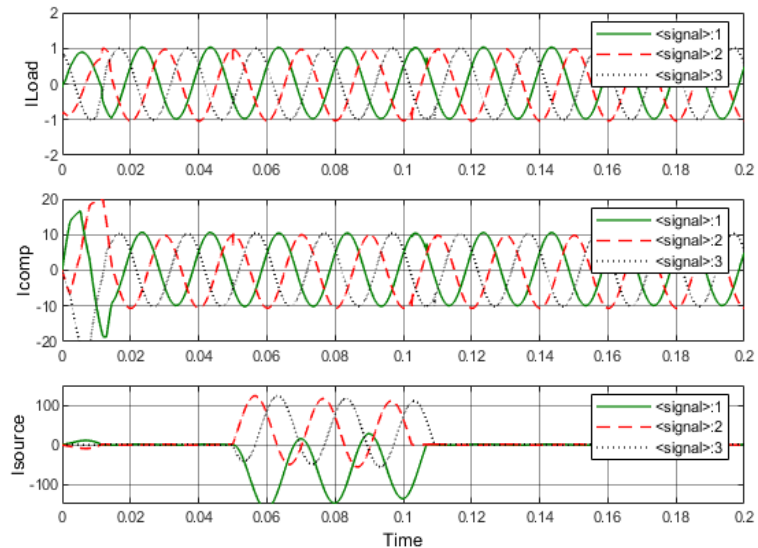

(b)

Figure 16. System response for three-phase to earth fault: (a) voltages response and (b) currents response
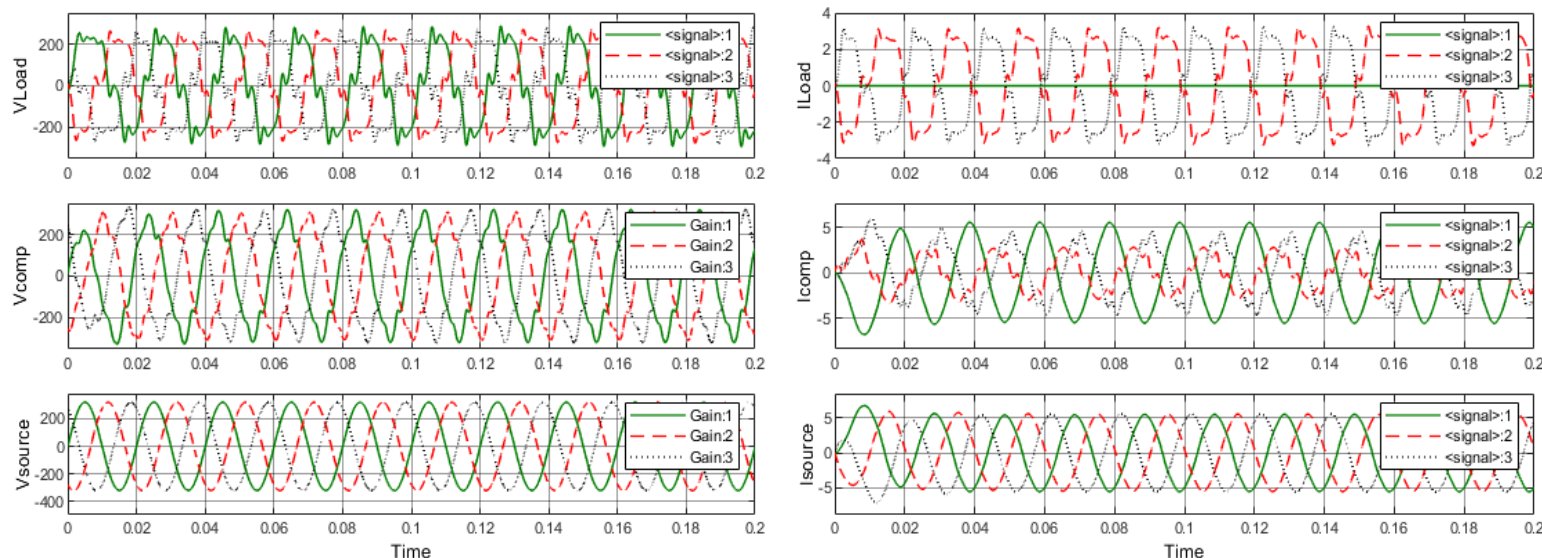

(a)

(b)

Figure 17. System response for one-phase outage of nonlinear balanced load: (a) voltages response and (b) currents response
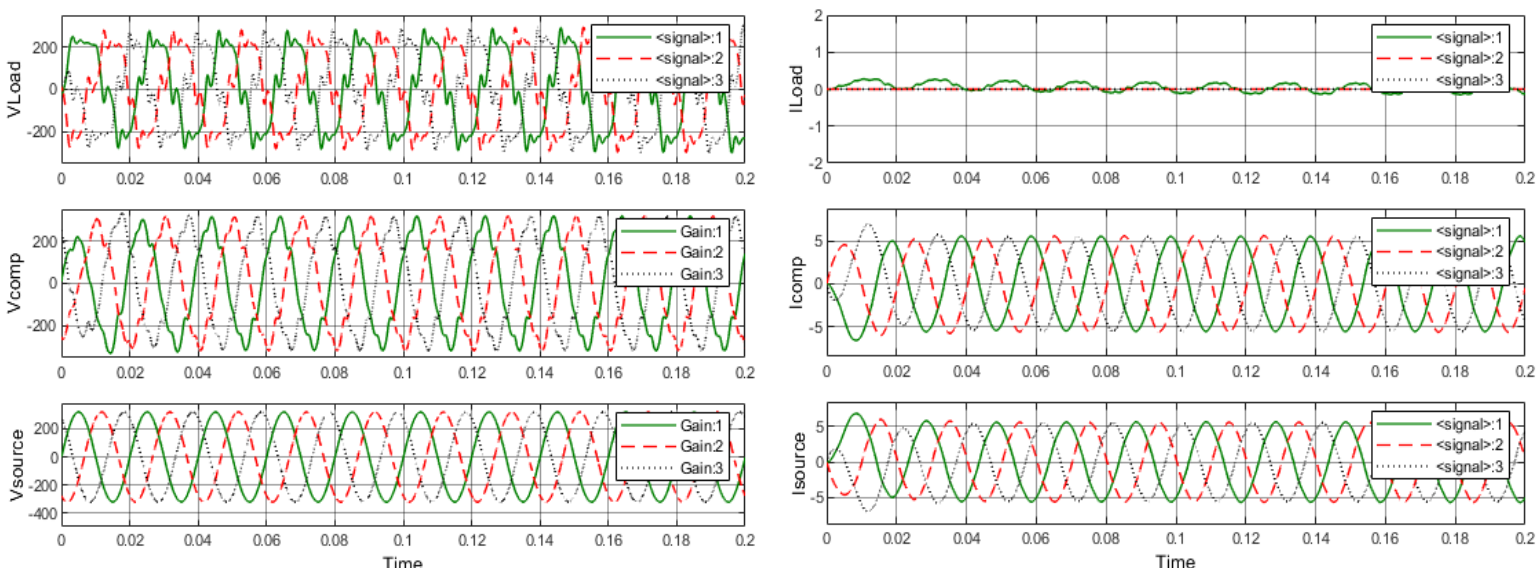

(a)

(b)

Figure 18. System response for two-phase outage of nonlinear balanced load: (a) voltages response and (b) currents response 
Table 3. Balanced and unbalanced non-linear load test, \% THD comparison

\begin{tabular}{|c|c|c|c|c|}
\hline \multirow{2}{*}{ Methods } & Balance system & Unbalence system & Balance system & Unbalence system \\
\hline & \multicolumn{2}{|c|}{ Before improvement } & \multicolumn{2}{|c|}{ After improvement } \\
\hline Proposed PSOANN & 28.54 & 16.3 & 0.81 & 1.03 \\
\hline SAPF [30] & 30.88 & 12.7 & 1.18 & 1.13 \\
\hline PPFO [22] & 11.4427 & 11.0 & 1.91 & 2.06 \\
\hline FO [22] & 11.4427 & 11.0 & 1.93 & 2.18 \\
\hline SRF [31] & 29.19 & - & 0.90 & - \\
\hline DPC [32] & 27.48 & - & 0.91 & - \\
\hline Conv. PI [33] & 28.01 & - & 3.88 & - \\
\hline GA [34] & 31.66 & - & 4.56 & - \\
\hline PSO [34] & 31.66 & - & 4.55 & - \\
\hline SCS [35] & 20.75 & - & 1.27 & - \\
\hline
\end{tabular}

\section{CONCLUSION}

The paper initially proposed to study the power quality by taking Erbil Mountain steel factory as a model and measuring all power quality disturbances for one week. The case measured and as it is seen, a high number of disturbances in frequency, current and voltage profiles were recorded. Then the paper proposed an optimization technique to improve the performance model of UPQC of the system for investigation in systems for low and medium line voltages, and it simulated with perform a hybrid active filter which consist of two filters shunt and series active filters connected to the distribution system to improve the waveform of source voltages and currents after deteriorated by nonlinear load system, and improving the power quality as a result. UPQC reacted very strongly to the system reduced current source THD from 28.54 to $0.81 \%$ at balanced nonlinear load and from 16.03 to $1.03 \%$ at unbalanced nonlinear load. The work is the practicability of the application of the obtained results for assessment of economic damages provoked by the asymmetry, non-sinusoidal, or voltage fluctuations which can be an adequate base for providing recommendations for enhancing the quality of supply in distribution system, commercial establishments, and industrial buildings.

\section{REFERENCES}

[1] J. D. Glover, M. S. Sarma, and T. Overbye, "Power system analysis \& design, SI version," Cengage Learning, Edition 5, 2012.

[2] E. L. Owen, "A history of harmonics in power systems," IEEE Industry Applications Magazine, vol. 4, no. 1, pp. 6-12, 1998, doi: $10.1109 / 2943.644881$

[3] H. A. Kazem, "Harmonic mitigation techniques applied to power distribution networks," Advances in Power Electronics, vol. 2013, Article ID, 591680, 2013, doi: 10.1155/2013/591680.

[4] M.-Y. Chan, K. K. Lee, and M. W. K. Fung, "A case study survey of harmonic currents generated from a computer centre in an office building," Architectural Science Review, vol. 50, no. 3, pp. 274-280, 2007, doi: 10.3763/asre.2007.5033.

[5] B. Singh, K. Al-Haddad, and A. Chandra, "A review of active filters for power quality improvement," IEEE Transactions on Industrial Electronics, vol. 46, no. 5, pp. 960-971, 1999, doi: 10.1109/41.793345.

[6] M. Diab, M. El-Habrouk, T. Abdelhamid, and S. Deghedie, "Survey of active power filters configurations," in 2018 IEEE International Conference on System, Computation, Automation and Networking (ICSCA), 2018, pp. 1-14: IEEE, doi: 10.1109/ICSCAN.2018.8541225.

[7] P. Salmeron and S. P. Litran, "A control strategy for hybrid power filter to compensate four-wires three-phase systems," IEEE Transactions on Power Electronics, vol. 25, no. 7, pp. 1923-1931, 2010, doi: 10.1109/TPEL.2010.2043687.

[8] D. Iannuzzi, L. Piegari, and P. Tricoli, "An active filter used for harmonic compensation and power factor correction: a control technique," in 2008 IEEE Power Electronics Specialists Conference, 2008, pp. 4631-4635: IEEE, doi: 10.1109/PESC.2008.4592697.

[9] S. Khan, B. Singh, and P. Makhija, "A review on power quality problems and its improvement techniques," in 2017 Innovations in Power and Advanced Computing Technologies (i-PACT), 2017, pp. 1-7: IEEE, doi: 10.1109/IPACT.2017.8244882.

[10] M. A. Taher, S. Kamel, F. Sayed, T. Khurshaid, and F. Jurado, "Load Shedding Reduction and Loadability Enhancement of Power System Using Shunt FACTS Devices," JES Journal of Electrical Systems,vol. 17, no. 1, 2021.

[11] M. Rungruanganukul and T. Siriborvornratanakul, "Deep Learning Based Gesture Classification for Hand Physical Therapy Interactive Program," in International Conference on Human-Computer Interaction, 2020, pp. 349-358: Springer, doi: 10.1007/978-3-030-49904-4_26.

[12] C. Kerdvibulvech and L. L. Chen, "The Power of Augmented Reality and Artificial Intelligence During the Covid-19 Outbreak," in International Conference on Human-Computer Interaction, 2020, pp. 467-476: Springer, doi: 10.1007/978-3-030-60117-1_34.

[13] E. Hossain, M. R. Tür, S. Padmanaban, S. Ay, and I. J. Khan, "Analysis and mitigation of power quality issues in distributed generation systems using custom power devices," IEEE Access, vol. 6, pp. 16816-16833, 2018, doi: 10.1109/ACCESS.2018.2814981.

[14] E. A. Al-Ammar, A. Ul-Haq, A. Iqbal, M. Jalal, and A. J. Anjum, "SRF based versatile control technique for DVR to mitigate voltage sag problem in distribution system," Ain Shams Engineering Journal, vol. 11, no. 1, pp. 99-108, 2020, doi: 10.1016/j.asej.2019.09.001.

[15] A. K. Jindal, A. Ghosh, and A. J. Joshi, "Interline unified power quality conditioner," IEEE Transactions on Power Delivery, vol. 22, no. 1, pp. 364-372, 2006, doi: 10.1109/TPWRD.2006.881581.

[16] A. Ghosh and G. Ledwich, "Power quality enhancement using custom power devices," Springer science \& business media, 2012.

[17] H. Fujita and H. Akagi, "The unified power quality conditioner: the integration of series-and shunt-active filters," Electrical Engineering Fields, vol. 13, no. 2, pp. 315-322, 1998, doi: 10.1109/63.662847. 
[18] V. Prakash, T. S. Reddy, S. T. Kalyani, and P. J. Karandikar, "Integration of photovoltac energy for improving power quality of UPQC," JES Journal of Electrical Systems, vol. 17, no. 1, pp. 105-120, 2021.

[19] K. P. Kumar, M. H. Vardhan, P. Vasu, and M. R. Krishna, "Power quality improvement using upqc with distributed generation," International Journal of Research and Analytical Reviews, vol. 6, no. 1, pp. 241-251, 2019.

[20] A. N. Alsammak and H. A. Mohammed, "Power quality improvement using fuzzy logic controller based unified power flow controller (UPFC)," Indonesian Journal of Electrical Engineering and Computer Science (IJEECS), vol. 21, no. 1, pp. 1-9, 2021, doi: 10.11591/ijeecs.v21.i1.pp1-9.

[21] A. Basam, M. Aifaa, M. Ariff, and S. N. Ramli, "Power quality improvement using dynamic voltage restorer in electrical distribution system: an overview," Indonesian Journal of Electrical Engineering and Computer Science (IJEECS), vol. 17, no. 1, pp. 86-93, 2020, doi: 10.11591/ijeecs.v17.i1.pp86-93.

[22] S. Mahaboob, S. K. Ajithan, and S. Jayaraman, "Optimal design of shunt active power filter for power quality enhancement using predator-prey based firefly optimization," Swarm and Evolutionary Computation BASE DATA, vol. 44, pp. 522-533, 2019, doi: 10.1016/j.swevo.2018.06.008.

[23] N. Alloui and C. Fetha, "Optimal design for hybrid active power filter using particle swarm optimization," Transactions on Electrical and Electronic Materials, vol. 18, no. 3, pp. 129-135, 2017.

[24] E. M. Thajeel, H. B. Daniyal, and M. H. Sulaiman, "Performance analysis of active power filter for harmonic compensation using PI-PSO," ARPN Journal of Engineering and Applied Sciences, vol. 10, no. 21, pp. 9885-91, 2015.

[25] O. M. Neda, "Optimal coordinated design of PSS and UPFC-POD using DEO algorithm to enhance damping performance," International Journal of Electrical and Computer Engineering (IJECE), vol. 10, no. 6, pp. 6111-6121, 2020, doi: 10.11591/ijece.v10i6.pp6111-6121.

[26] R. H. AL-Rubayi and L. G. Ibrahim, "Enhancement transient stability of power system using UPFC with M-PSO," Indonesian Journal of Electrical Engineering and Computer Science (IJEECS), vol. 17, no. 1, pp. 61-69, 2020, doi: 10.11591/ijeecs.v17.i1.pp61-69.

[27] M. Takruri, M. K. A. Mahmoud, and A. Al-Jumaily, "PSO-SVM hybrid system for melanoma detection from histo-pathological images," International Journal of Electrical and Computer Engineering (IJECE), vol. 9, no. 4, p. 2941, 2019, doi: 10.11591/ijece.v9i4.pp2941-2949.

[28] M. Z. M. Tumari, A. F. Z. Abidin, A. Subki, Ab Wafi Ab Aziz, M. Saealal, and M. A. Ahmad, "Liquid slosh control by implementing model-free PID controller with derivative filter based on PSO," Indonesian Journal of Electrical Engineering and Computer Science (IJEECS), vol. 18, no. 2, p. 750, 2020, doi: 10.11591/ijeecs.v18.i2.pp750-758.

[29] L. D. Sahu and S. P. Dubey, "ANN based hybrid active power filter for harmonics elimination with distorted mains," International Journal of Power Electronics and Drive Systems, vol. 2, no. 3, p. 241, 2012, doi: 10.11591/ijpeds.v2i3.276.

[30] A. A. Imam, R. Sreerama Kumar, and Y. A. Al-Turki, "Modeling and simulation of a PI controlled shunt active power filter for power quality enhancement based on PQ theory," Electronics, vol. 9, no. 4, p. 637, 2020, doi: 10.3390/electronics9040637.

[31] E. Sundaram and M. Venugopal, "On design and implementation of three phase three level shunt active power filter for harmonic reduction using synchronous reference frame theory," International Journal of Electrical Power and Energy Systems, vol. 81, pp. 40-47, 2016, doi: 10.1016/j.ijepes.2016.02.008.

[32] A. Chaoui, J.-P. Gaubert, and F. Krim, "Power quality improvement using DPC controlled three-phase shunt active filter," Electric Power Systems Research, vol. 80, no. 6, pp. 657-666, 2010, doi: 10.1016/j.epsr.2009.10.020.

[33] A. Sakthivel, P. Vijayakumar, A. Senthilkumar, L. Lakshminarasimman, and S. Paramasivam, "Experimental investigations on ant colony optimized PI control algorithm for shunt active power filter to improve power quality," Control Engineering Practice, vol. 42, pp. 153-169, 2015, doi: 10.1016/j.conengprac.2015.04.013.

[34] T. Parithimar Kalaignan, "Power quality enhancement by minimizing current harmonics using soft computing based shunt active and hybrid filters," Computer Science, 2015.

[35] N. Senthilnathan and T. Manigandan, "Design and development of three phase shunt active filter with balanced and unbalanced supply," International Journal of Electrical Engineering, vol. 5, no. 3, pp. 275-291, 2012.

\section{BIOGRAPHIES OF AUTHORS}

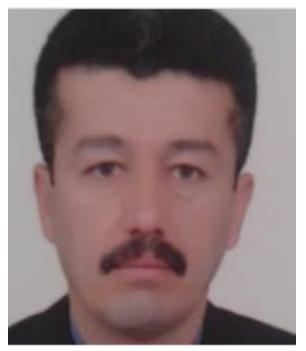

Ismael Kareem Saeed (iD $8 \mathrm{SC}$ P was born in Erbil, Iraq. He received his M.Sc. degree from Salahaddin university-Erbil in 2002. His research interests include power quality and power system analysis. Now he is work in the Electrical Engineering Department at the College of Engineering at the Salahaddin University-Erbil. He can be contacted by email: ismael.saeed@su.edu.krd.

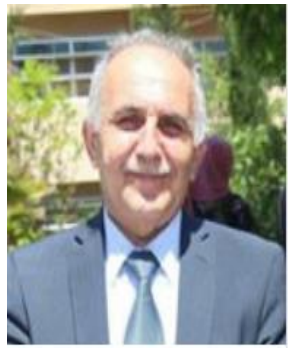

Kamal Sheikhyounis (D) 8d SC P was born in Erbil, Iraq. He received his M.Sc. degree from Belarusian Polytechnic Institute, Minsk, Belorussia in Electrical Engineering in 1980. He received his PHD from Moscow Energetic Institute in 1991. His research interests include power system analysis. Now he is an assistant professor and a faculty member in the Electrical Engineering Department at the College of Engineering at the Salahaddin University-Erbil. He can be contacted by email: younis@ieee.org. 